\title{
BEDEN EĞiTiMi DERSINDE PROBLEM ÇÖZME BECERISI VE SINIF IKLIMI: IKINCI KADEME ILKÖĞRETIM ÖĞRENCILERI ÜZERINE BIR ÇALIŞMA
}

\author{
A.Meliha CANPOLAT ${ }^{1}$ \\ Zişan KAZAK ÇETINKALP ${ }^{1}$ \\ Murat ÖZŞAKER ${ }^{2}$
}

Geliş Tarihi: 23.10 .2012

Kabul Tarihi: 07.03.2013

\section{ÖZET}

Bu çalışmanın amacı, ikinci kademe ilköğretim çağındaki öğrencilerin beden eğitimi dersinde problem çözme becerilerini ve sınıf iklimi düzeylerini belirlemek ve beden eğitimi ve sınıf ikliminin problem çözme becerisi üzerindeki etkisini incelemektir. Çalışmada, $295 '$ ' kız $\left(X_{\text {yas }} \pm S s=12.90 \pm 0.81\right)$ ve 253 'ü erkek $\left(X_{\text {yas }} \pm S s=12.89 \pm 0.81\right)$ olmak üzere toplam 548 öğrenci yer almaktadır. Öğrencilerin problem çözme becerilerini ve beden eğitimi sınıf iklimi düzeylerini belirlemek için Çocuklar için Problem Çözme Envanteri ve Beden Eğitimi Sınıf İklimi Ölçeği kullanılmışıı. Verilerin değerlendirilmesinde bağımsız gruplar için t testi, Pearson korelasyon analizi ve adımsal çoklu regresyon analizi kullanılıştır. Sonuçlar, Öğrenme/ustalık alt boyutunun problem çözme becerisi güven boyutuna öngörü sağladığını göstermektedir.

Anahtar kelimeler: Problem Çözme, Sınıf İklimi, Beden Eğitimi Dersi

\section{PROBLEM SOLVING SKILLS AND CLASS CLIMATE IN PHYSICAL EDUCATION COURSE: A STUDY ON SECONDARY SCHOOL STUDENTS}

\begin{abstract}
The purpose of this study was to determine the secondary school students' problems solving skills and class climate in physical education course, and also to examine effect of problem solving skills on physical education class climate. The participants of this study are 548 students who are 295 girls $\left(\mathrm{M}_{\text {age }} \pm \mathrm{Sd}=12.90 \pm 0.81\right)$ and 253 boys $\left(\mathrm{M}_{\mathrm{age}} \pm \mathrm{Sd}=12.89 \pm 0.81\right)$ with a mean of age $12.89 \pm 0.81$ years. Problem Solving Inventory for Children and the Physical Education Class Climate Scale were used to determine students' problem solving and physical education class climate levels, respectively. Independent sample t test, Pearson correlation analysis and multiple regression analysis with stepwise were used to analyze data. Results were showed that learning/mastery subscale was the best significant predictor of confidence to problem solving skill subscale.
\end{abstract}

Key Words: Problem Solving, Class Climate, Physical Education Course

\section{GiRiş}

Ergenliğe geçiş dönemi, önemli davranışların kazanıldığı en önemli dönemlerden biridir. Bu dönemde çocuklara, toplum içinde diğer insanlarla nasıl uyum içinde yaşayacakları ve yaşamlarını daha iyi bir biçimde nasıl sürdüreceklerine ilişkin gerekli olan temel bilgi ve beceriler kazandırılmak hedeflenmektedir (1). Özellikle karşılaşacakları sorunlarla başa çıkma becerilerine kazandıııması ve hayatları boyunca karşı karşıya kaldıkları problemlerin çözümüne dair uygun çözüm yolları aramaya çalışmasına yönelik davranış örüntüleri oluşturması önemlidir.

Kişinin günlük yaşamda karşılaştığı sorunlu durumlarda etkili başa çıkma yolunu bulabilmek için geliştirdiği ve ürettiği bilişsel, duyuşsal ve davranışsal süreç, problem çözme olarak tanımlanmaktadır (2). Kişinin karşılaştıkları sorunların üstesinden gelmesi, diğer bir deyişle problem çözme becerisi, yaşamının her döneminde etkili olan ve bütün etkinliklerde yer alan önemli bir yaşam becerisidir. Bu beceri, kişinin kendisi ve çevresi ile baş etme sürecinde önemli etkiye sahiptir (3). Problem çözme becerisi, çocukluk çağından itibaren öğrenilen, okul yıllarında ise geliştirilen bir davranıştır (4). Şahin, Şahin ve Heppner (1993)'in yaptıkları bir çalışmada, kendisini problem çözmede yeterli olarak algılayan bireylerin, kişiler arası ilişkilerde daha girişken ve daha olumlu benlik algısına sahip olduklarını

1 Ege Üniversitesi, Beden Eğitimi ve Spor Yüksekokulu, Bornova, İzmir

2 Celal Bayar Üniversitesi, Beden Eğitimi ve Spor Yüksekokulu, Manisa 
belirlemişlerdir(5). Bunun yanında, etkili problem çözen bireylerin bağımsız ve yaratıcı düşünme becerilerinin ve sosyal yeterliklerinin daha fazla olduğu, kendilerine güvenen kişiler oldukları ifade edilmektedir (6). Kişinin yeni sorunları çözme yeteneğine olan inancı, bir başka deyişle problem çözme becerisine olan güveni (7), karşılaştıkları güçlükleri ortadan kaldırmaya ilişkin çabasını da desteklemektedir. Ayrıca, bireyin karşılaştığı sorun karşısında problemin çözümü hakkındaki ayrıntılı olarak bilgi toplamayı düşünüp düşünmediği, uyguladığı çözüm başarısız olursa o problemle başa çıkma konusunda şüpheye düşüp düşmediği, problemi çözer ise problemi çözme konusunda neyin işe yaradığını düşünüp düşünmediği (8) bireyin probleme ilişkin çabasının şiddetini ve yönünü belirleyecektir. Buna ek olarak bireyin içinde bulunduğu sosyal ortamın onun problem çözme becerisi üzerinde önemli etkisi olduğu ileri sürülmektedir (9). Özellikle, kişilerarası süreci ve değerlendirmeyi içeren öğrenme ortamlarında duyuşsal ve sosyal koşulları ifade eden güdüsel iklim (10) yapısının, problem çözme becerisi üzerindeki etkisi olduğu bilinmektedir.

Güdüsel iklimde, ustalık ve performans temelli unsurlar olmak üzere, iki boyut üzerinde durulmaktadır (11). Bu boyutlardan ustalık iklimi, aktiviteye yönelik pozitif tutum, doyum hissi, yüksek yeterlik algısı, mücadele gerektiren görevler seçme, üst düzeyde içsel güdülenme, öğrenme sürecine ve çabaya değer verme gibi uyumlayıcı güdüsel örüntülerle yakından ilişkilidir (12). Ustalık güdüsel iklimin, kişi referanslı gelişimin ve çabanın öğretmen tarafından vurgulandığı ve başarının bireysel gelişime göre değerlendirildiği zaman belirginleştiği ifade edilmektedir (13). Buna karşın, performans iklimi, sorunlara yönelik negatif tutumlar, başarının çaba göstermekten çok yeteneğe bağlı olduğu inancı, bıkkınlık gibi daha az uyumlayıcı bilişsel ve duyuşsal sonuçlarla ilişkili olduğu belirtilmektedir (12). Dolayısıyla bireyin içinde bulunduğu ortamda algıladığı hedef yapısının diğer bir deyişle güdüsel iklimin, onun problem çözmeye ilişkin sergileyeceği davranışı şekillendirmektedir (14).

Problem çözme becerisi ile ilgili yapılan çalışmalarda, problem çözme becerisinin beceri eğitimi yoluyla geliştirilebileceği $(15,16)$ de ileri sürülmektedir. Özellikle, ilköğretim çağındaki çocukların problem çözme becerilerini geliştirmesinin en iyi yollarından birisi olarak fiziksel aktivite ortamları düşünülmektedir (17). Fiziksel aktivite ortamlarına katılan bireylerin herhangi bir problemle karsılaştıklarında, problem çözme düşüncesi yolu ile sorunu çözmeye çalıştıkları ve problem çözme düşüncesi sayesinde kendi mevcut yetenek ve becerilerinin amacına yönelik olarak kullanabildikleri ifade edilmektedir (18). Bu çalışmada da problem becerisi ve algılanan güdüsel iklim arasındaki bu bağ, beden eğitimi ortamları açısından ele alınmıştır. Bireyin beden eğitimi dersi içerisinde algıladığı güdüsel iklim yapısı ile problem çözme becerileri arasındaki ilişkinin belirlenmesi ve bu yapıların cinsiyetlere göre nasıl farklılaştığının ortaya konması amaçlanmıştır. Özellikle ergenliğe geçiş döneminde olan bireylerde, bu ilişkinin incelenmesi ve yapılacak olan açıklamaların bireylerin kişilik yapısının olumlu biçimde gelişmesine önemli katkılar sağlayacağı düşünülmektedir.

\section{YÖNTEM}

\section{Araştırma Grubu}

Bu çalışmaya, 2010 - 2011 Eğitim-Öğretim yılı içerisinde Aydın Merkez İkinci Kademe İlköğretim okullarında

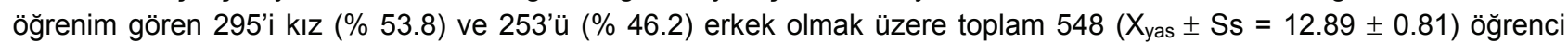
katılmıştır. Çalışmaya katılan kız öğrencilerin yaş ortalamalarının $12.90 \pm 0.81$ ve erkek öğrencilerin yaş ortalamalarının $12.89 \pm 0.81$ olduğu belirlenmiştir. Öğrencilerin 205'inin altıncı sınıf, 197'sinin yedinci sınıf ve 146'sının sekizinci sınıfta öğrenim gören öğrenciler olduğu gözlenmiştir.

\section{Veri Toplama Araçları}

Çocuklar için Problem Çözme Envanteri. İlköğretim düzeyindeki öğrencilerin problem çözme becerisini değerlendirmek amacıyla Serin, Bulut Serin ve Saygılı (2010) tarafından geliştirilmiş olan "Çocuklar için Problem Çözme Envanteri-ÇPÇE" kullanılmıştır (19). Envanter, 24 maddeden oluşmakta ve 3 alt boyutu (Problem çözme becerine güven:12 madde, Özdenetim: 7 madde ve Kaçınma: 5 madde) içermektedir. Her madde 1 (Hiçbir zaman böyle davranmam) ile 5 (Her zaman böyle davranırım) arasında değişen beşli değerlendirme basamağına sahiptir. Geliştirilen 24 maddelik ölçüm aracına ilişkin yapılan yapı analizi sonuçlarına göre, envanterin toplam varyansın \% 42.26’sını açıkladığı belirlenmiştir. Bunun yanında, yapılan doğrulayıcı faktör analizi sonuçlarında da üç faktör modeli desteklenmiştir $\left(X^{2} / \mathrm{df}=2.49, \mathrm{RMSEA}=0.051, \mathrm{GFI}=0.92, \mathrm{CFI}=0.90\right)$. İç tutarlık katsayıları ise, Problem çözme becerisine güven için 0.85; Özdenetim için 0.78 ve Kaçınma için 0.66 olarak belirlenmiştir. Test-tekrar test güvenirliği ise, Problem çözme becerisine güven için 0.84; Özdenetim için 0.79 ve Kaçınma için 0.70'dir (19).

Beden Eğitimi Sınıf İklim Ölçeği (BESiö) : Beden Eğitimi Sınıf İklim Ölçeği (Physical Education Class Climate Scale), Goudas ve Biddle (1994) tarafından geliştirilmiş, Canpolat ve Kazak Çetinkalp (2012) tarafından Türkçe uyarlaması gerçekleştirilen bir ölçüm aracıdır $(20,21)$. Ölçek, 28 maddeden oluşmakta ve 6 alt boyutu içermektedir: Sınıf ustalık yönelimi, Öğretmenin ustalık yönelimi desteği, Öğrencinin seçim algısı, Öğretmen desteği, Sınıf performans yönelimi ve Hatalar hakkında endişeler. Sınıf ustalık yönelimi, Öğretmenin ustalık yönelimi desteği, Öğrencinin seçme algısı ile Öğretmen desteği alt faktörleri "Ustalık" boyutu olarak ve Sınıf performans yönelimi ile Hatalar hakkında endişeler ise "Performans" boyutu olarak ta değerlendirilmektedir. Ölçek yargıların beş değerlendirme basamağına 
(1=Hiç katılmıyorum - 5=Tamamen Katılıyorum) göre yanıtlanmaktadır. İkinci düzey iki faktörlü ölçme modeli için hesaplanan uyum indeksleri $x^{2} / \mathrm{df}=2.37, \mathrm{RMSEA}=0.044, \mathrm{SRMR}=0.05, \mathrm{GFI}=0.92, \mathrm{NNFI}=0.93$ ve $\mathrm{CFI}=0.93$ olarak bulunmuştur. İkinci düzey altı faktörlü model için iç tutarlık değerleri, performans için 0.79 ve öğrenme/ustalık için 0.90 olarak bulunmuştur (21).

\section{Verilerin Toplanması ve Analizi}

Çalışma Aydın ilinde bulunan iki ilköğretim okulu öğrencileri üzerinde gerçekleştirilmiştir. Araştırmacılar uygulama ile ilgili gerekli izinleri alındıktan sonra, beden eğitimi dersinde kişisel bilgi formu, Çocuklar için Problem Çözme Envanteri ve Beden Eğitimi Sınıf İklim Ölçeği'ni içeren anket formunu öğrencilere uygulamışlardır. Gerekli açıklamalar, uygulayıcılar tarafından yapılmıştır. Sonuçlar, katılımcıların kendilerini ifade ettikleri yanıtlarla sınırlıdır. Çalışmaya katılanların ölçekleri içtenlikle yanıtladıkları varsayılmıştır. Verilerin istatistiksel analizi ve değerlendirilmesi sırasında Bağımsız gruplar için t testi, Pearson korelasyon analizi ve Adımsal çoklu regresyon analizi kullanılarak elde edilen veriler tablolaştırılarak sunulmuştur.

\section{BULGULAR}

Tablo 1'de araştırmaya katılan 295 kız ve 253 erkek öğrencinin, Çocuklar için Problem Çözme Envanterinin "Problem Çözme Becerisine Güven”, "Özdenetim”, "Kaçınma” ve Beden Eğitimi Sınıf İklim Ölçeği'nin "Öğrenme/Ustalık” ve "Performans" alt boyutlarına ilişkin t testi sonucu görülmektedir. Bu sonuca göre, kız ve erkek öğrencilerin "Kaçınma" $(t=2.82, p<0.01)$ alt boyutu ortalama puanları arasında istatistiksel olarak anlamlı farkın olduğu bulunmuştur. Diğer bir deyişle, erkek öğrencilerine ait "Kaçınma" alt boyutuna ilişkin ortalama puanlarının, kız öğrencilerin ortalama puanından daha düşük olduğu saptanmıştır. Buna ek olarak, Beden Eğitimi Sınıf İklim Ölçeği'nin "Öğrenme/Ustalık” (t = -1.97, p < 0.05) alt boyutunun ortalama puanları arasında da anlamlı farklılık belirlenmiştir. Kız öğrencilerin ortalama puanlarının erkek öğrencilere göre daha düşük olduğu saptanmıştır.

Tablo 1. Cinsiyete Göre Problem Çözme Becerileri ve Beden Eğitimi Sınıf İklimi alt boyutlarına ilişkin t testi Sonuçları

\begin{tabular}{llcccc}
\hline & Cinsiyet & $\mathrm{n}$ & $\overline{\mathrm{X}}$ & $\mathrm{Ss}$ & $\mathrm{t}$ \\
\hline Problem Çözme & Kız & 295 & 3.80 & 0.79 & \\
Becerisine Güven & Erkek & 253 & 3.92 & 0.75 & -1.90 \\
\cline { 2 - 6 } Özdenetim & Kız & 295 & 2.93 & 0.93 & \\
\multirow{3}{*}{ Kaçınma } & Erkek & 253 & 3.00 & 0.98 & -0.92 \\
\cline { 2 - 6 } & Kız & 295 & 3.63 & 1.02 & \multirow{2}{*}{ Öğrenme/Ustalık } \\
\cline { 2 - 6 } & Erkek & 253 & 3.37 & 1.15 & $2.82^{* *}$ \\
\cline { 2 - 6 } Performans & Kız & 295 & 3.91 & 0.70 & \multirow{2}{*}{$-1.97^{*}$} \\
\cline { 2 - 6 } & Krkek & 253 & 4.03 & 0.67 & \multirow{2}{*}{0.85} \\
\hline
\end{tabular}

${ }^{*} p<0.05,{ }^{* *} p<0.01$

Kız ve erkek öğrencilerin Problem Çözme Envanteri ile Beden Eğitimi Sınıf İklim Ölçeği'nin alt boyutları arasındaki ilişkiyi gösteren Pearson korelasyon katsayıları Tablo 2'de sunulmuştur. Kız öğrencilerin korelasyon tablosuna bakıldığında; Problem çözme becerisinin, Kaçınma ( $r=0.28, p<0.01)$, Öğrenme/Ustalık $(r=0.48, p<0.01)$ ve Performans $(r=0.30, p<0.01)$ alt boyutları ile düşük ve pozitif anlamlı ilişki gösterdiği belirlenmiştir. Özdenetim alt ölçeğinin ise, Kaçınma ( $r=0.56, p<0.01)$ alt boyutu ile orta düzeyde ve pozitif bir ilişki, Performans $(r=-0.27, p<0.01)$ alt boyutuyla düşük ve negatif anlamlı ilişki gösterdiği gözlenmiştir. Kaçınma alt boyutunun Öğrenme/Ustalık $(r=0.19, p$ $<0.01)$ alt boyutuyla düşük ve pozitif anlamlı ilişki gösterdiği, bunun yanında Öğrenme/Ustalık ile Performans $(r=0.40, p$ < 0.01) alt boyutları arasında orta düzeyde ve pozitif bir ilişkisi olduğu belirlenmiştir. Erkek öğrencilerin korelasyon tablosuna bakıldığında ise; Problem çözme becerisinin, Özdenetim ( $r=-0.16, p<0.05)$ ile negatif ve anlamlı, Öğrenme/Ustalık $(r=0.53, p<0.01)$ ve Performans $(r=0.44, p<0.01)$ alt boyutları ile pozitif ve anlamlı ilişkisi olduğu görülmüştür. Özdenetim alt ölçeğinin ise, Kaçınma $(r=0.63, p<0.01)$ alt boyutu ile orta düzeyde ve pozitif bir ilişkinin, Performans ( $r=-0.24, p<0.01)$ alt boyutuyla düşük ve negatif anlamlı ilişki gösterdiği gözlenmiştir. Kaçınma alt boyutunun Performans $(r=-0.18, p<0.01)$ alt boyutuyla negatif ve anlamlı ilişki gösterdiği, bunun yanında Öğrenme/Ustalık ile Performans $(r=0.64, p<0.01)$ alt boyutu arasında orta düzeyde ve pozitif bir ilişki olduğu belirlenmiştir. 
Tablo 2. Kız ve erkek öğrencilerin Problem Çözme Envanteri ile Beden Eğitimi Sınıf İklim Ölçeği'nin alt boyutları arasındaki ilişki

\begin{tabular}{|c|c|c|c|c|c|c|c|c|}
\hline & \multicolumn{4}{|c|}{$\mathrm{K} \mathrm{IZ}$} & \multicolumn{4}{|c|}{ Erkek } \\
\hline & 1 & 2 & 3 & 4 & 1 & 2 & 3 & 4 \\
\hline 1. Problem çözme becerisine güven & 1.00 & & & & 1.00 & & & \\
\hline 2. Özdenetim & 0.11 & 1.00 & & & $-0.16^{*}$ & 1.00 & & \\
\hline 3. Kaçınma & $0.28^{* *}$ & $0.56^{\star *}$ & 1.00 & & 0.02 & $0.63^{* *}$ & 1.00 & \\
\hline 4. Öğrenme/Ustalık & $0.48^{* *}$ & 0.01 & $0.19^{* *}$ & 1.00 & $0.53^{* *}$ & -0.11 & 0.02 & 1.00 \\
\hline 5. Performans & $0.30^{* *}$ & $-0.27^{\star *}$ & -0.01 & $0.40^{* *}$ & $0.44^{\star *}$ & $-0.24^{* *}$ & $-0.18^{* *}$ & $0.64^{* *}$ \\
\hline
\end{tabular}

${ }^{*} p<0.05 ;{ }^{* *} p<0.01$

Problem çözme becerilerini öngörme bakımından Beden Eğitimi Sınıf İklim Ölçeği'nin alt boyutlarının incelenmesine yönelik adımsal çoklu regresyon analizi sonuçları incelendiğinde (Tablo 3 ), kız öğrencilerde Öğrenme/Ustalık ( $\beta=0.42, t=7.57, p<0.001)$ ve Performans iklim $(\beta=0.14, t=2.45, p<0.05)$ yapılarının problem çözme becerisine güven boyutuna pozitif öngörü sağladığı belirlenmiştir. Öğrenme/Ustalık iklim yapısının toplam varyansın \% 23'ünü, Performans iklim yapısının ise varyansın \% 1'ini açıkladığı görülmektedir. Özdenetim alt boyutu ele alındığında, kız öğrencilerde Performans $(\beta=-0.33, t=-5.44, p<0.001)$ iklim yapısının negatif ve Öğrenme/Ustalık $(\beta=$ $0.15, t=2.40, p<0.05)$ iklim yapısının Özdenetim alt boyutuna pozitif öngörü sağladığı belirlenmiştir. Performans iklim yapısının ise varyansın \% 7'sini, Öğrenme/Ustalık iklim yapısının toplam varyansın \%2'sini, açıkladığı görülmektedir. Son olarak, Öğrenme/Ustalık $(\beta=0.19, t=3.23, p<0.001)$ iklim yapısının Kaçınma alt boyutunu pozitif belirleyicisi olduğu ve toplam varyansın \% 3'ünü açıkladığı belirlenmiştir. Erkek öğrencilerde ise, Öğrenme/Ustalık $(\beta=0.43, t=6.25, p<0.001)$ ve Performans iklim $(\beta=0.16, t=2.34, p<0.05)$ yapılarının problem çözme becerisine güven boyutuna pozitif öngörü sağladığı belirlenmiştir. Öğrenme/Ustalık iklim yapısının toplam varyansın \%29'ünü, Performans iklim yapısının ise varyansın \% 1'ini açıkladığı görülmektedir. Özdenetim alt boyutu ele alındığında, Performans $(\beta=-0.24, t=-3.87, p<$ $0.001)$ iklim yapısının Özdenetim alt boyutuna negatif öngörü sağladığı belirlenmiştir. Performans iklim yapısının ise varyansın \% 6'sını açıkladığı görülmektedir. Son olarak, Performans $(\beta=-0.33, t=-4.13, p<0.001)$ iklim yapısının Kaçınma alt boyutunu negatif belirleyicisi olduğu, buna karşın Öğrenme/Ustalık $(\beta=0.23, t=2.86, p<0.05)$ iklim yapısının pozitif belirleyici olduğu bulunmuştur. Performans iklim yapısının ise varyansın \% 3'ünü, Öğrenme/Ustalık iklim yapısının toplam varyansın \% 3'ünü açıkladığı görülmektedir.

Tablo 3. Problem Çözme Becerilerini Öngörme Bakımından Beden Eğitimi Sınıf İklim Ölçeği'nin Alt Boyutlarının İncelenmesine Yönelik Çoklu Regresyon Analizi Sonuçları (N=548)

\begin{tabular}{|c|c|c|c|c|c|c|c|}
\hline & & $R^{2}$ & $\begin{array}{c}R^{2} \\
\text { Değişimi }\end{array}$ & $B$ & $S E$ & $\beta$ & $F$ \\
\hline \multirow{8}{*}{$\mathrm{K} \mathrm{IZ}$} & Problem çözme beceris & & & & & & \\
\hline & Öğrenme/Ustalık & 0.23 & 0.23 & 0.47 & 0.06 & 0.42 & $85.28^{* * *}$ \\
\hline & Performans & 0.24 & 0.01 & 0.16 & 0.06 & 0.14 & $46.37^{\star * *}$ \\
\hline & Özdenetim & & & & & & \\
\hline & Performans & 0.07 & 0.07 & -0.44 & 0.08 & -0.33 & $23.46^{\star * *}$ \\
\hline & Öğrenme/Ustalık & 0.09 & 002 & 0.19 & 0.08 & 0.15 & $14.80^{\star \star *}$ \\
\hline & Kaçınma & & & & & & \\
\hline & Öğrenme/Ustalık & 0.03 & 0.03 & 0.27 & 0.08 & 0.19 & $10.44^{\star * *}$ \\
\hline \multirow{8}{*}{ Erkek } & Problem çözme beceris & & & & & & \\
\hline & Öğrenme/Ustalık & 0.29 & 0.29 & 0.48 & 0.08 & 0.43 & $100.22^{* * *}$ \\
\hline & Performans & 0.30 & 0.01 & 0.17 & 0.07 & 0.16 & $53.73^{\star * *}$ \\
\hline & Özdenetim & & & & & & \\
\hline & Performans & 0.06 & 0.06 & -0.33 & 0.09 & -0.24 & $14.98^{\star \star *}$ \\
\hline & Kaçınma & & & & & & \\
\hline & Performans & 0.03 & 0.03 & -0.54 & 0.13 & -0.33 & $8.67^{* *}$ \\
\hline & Öğrenme/Ustalık & 0.06 & 0.03 & 0.39 & 0.14 & 0.23 & $8.55^{\star \star *}$ \\
\hline
\end{tabular}

${ }^{* *} p<0.01,{ }^{* * *} p<0.001$

\section{TARTIŞMA VE SONUÇ}

Bu çalışmada, ikinci kademe ilköğretim düzeyindeki kız ve erkek öğrencilerin beden eğitimi dersinde problem çözme becerileri ve sınıf iklimi düzeylerinin belirlenmesi, bunun yanında beden eğitimi sınıf iklimi düzeylerinin problem çözme becerileri üzerindeki etkisinin incelemesi hedeflenmiştir. 
Kız ve erkek öğrencilerin çalışma değişkenlerine ilişkin ortalama puanlarında farklılık olup olmadığı incelendiğinde, kız öğrencilerine ait Kaçınma alt boyutuna ilişkin ortalama puanın, erkek öğrencilerin ortalama puanından daha yüksek olduğu; buna karşın erkek öğrencilerine ait Öğrenme/ustalık alt boyutuna ilişkin ortalama puanlarının kız öğrencilere göre daha yüksek olduğu saptanmıştır. Haeffel (2011) kadınların kaçınma düzeylerinin erkeklere göre anlamlı bir şekilde yüksek olduğunu belirlemiştir (22). Buna karşın Bell ve D'Zurilla (2009)'nın üniversite öğrencileri üzerinde yapmış oldukları çalışmalarında kadın ve erkek öğrenciler arasında kaçınma stili açısından anlamlı bir farklılığın olmadığına işaret etmişlerdir (23). Diğer bir çalışmada D’Zurilla, Maydeu-Olivares and Kant (1998), genç yetişkin bireylerle karşılaştırıldığında, orta yaş bireylerin kaçınma sitilinde daha düşük puanlara sahip olduğu belirlemişlerdir (24). Bu çalışmalara ek olarak Güçray (2005) tarafından lise öğrencileri üzerinde yapılan bir çalışmada da, kaçınma stili açısından cinsiyetler arasında istatistiksel olarak anlamlı fark olmadığı ifade edilmiştir (25). Öğrenme/ustalık alt boyutuna ilişkin elde edilen çalışma bulgularına paralel olarak Moreno-Murcia, Hernandez, Vaillo ve Camacho (2012)'nun beden eğitimi sınıflarında 984 öğrenci üzerinde güdülenme ve fiziksel benlik kavramını ele aldıkları çalışma bulgularında, erkek öğrencilerin görev katılımlı güdüsel iklim düzeylerinin kız öğrencilere göre daha yüksek olduğunu göstermektedir (26). Buna karşın Bakirtzoglou ve loannou (2011) ve Moreno-Murcia, Gimeno ve Gonzalez-Cutre Coll (2008) kız öğrencilerin görev katılımlı güdüsel iklim düzeylerinin erkek öğrencilerle kıyaslandığında, yüksek olduğunu belirtmişlerdir $(27,28)$.

Problem Çözme Becerisi alt boyutları ile beden eğitimi sınıf iklimi düzeyleri arasındaki ilişkiyi ortaya koymaya yönelik yapılan analiz sonuçlarında, hem kız hem erkek öğrencilerde problem çözme becerisine güven boyutunun öğrenme/ustalık iklim ve performans iklim boyutlarıyla pozitif ve anlamlı ilişki gösterdiği belirlenmiştir. Özdenetim boyutunun hem kız hem erkek öğrencilerde performans iklim boyutu ile ilişkili olduğu belirlenmiştir. Bu çalışma bulgularıyla ilişkili olarak literatürdeki diğer çalışmalar incelendiğinde, Ntoumanis, Biddle ve Haddock (1999)'ın, üniversitede okuyan 356 sporcu üzerinde yapmış oldukları çalışmalarında, performans ve ustalık ilkim yapısıyla kontrol duygusu arasında istatistiksel olarak anlamlı ilişki olmadığını belirlemişlerdir (29). Liukkonen, Barkoukis, Watt ve Jaakkola (2010) özerklik ile görev katılımlı iklim arasında pozitif ve anlamlı ilişki olduğunu, ego katılımlı iklim ile ise aralarında anlamlı ilişki olmadığını ileri sürmüşlerdir (30). Aynı şekilde Standage, Duda ve Ntoumanis (2003), ustalık iklimin özerklik yapısı ile ilişkili olduğunu, bunun yanında performans iklimin özerklik arasında anlamlı ilişki olmadığını belirlenmişlerdir (31). Yine Quested ve Duda (2009) özerkliğin görev iklim ile pozitif, ego iklim ile negatif ilişkili olduğunu ortaya koymuşlardır. Kaçınma stratejileri mevcut durumu değiştirmek için girişimde bulunmama, çaba göstermeme ile karakterize edilmektedir (32). Ntoumanis, Biddle ve Haddock (1999), başarı hedefi kuramcılarının (Örn.; 10; 33), öğrenme/ustalık iklimi algıları yüksek olan bireylerin stres ve negatif duygulara karşı çok duyarlı olmadıklarını belirtmişler ve bundan dolayı bu kişilerin çaba gibi problem odaklı stratejileri daha fazla kullanabilecekleri ileri sürmüşlerdir (29). Yine aynı çalışmada, ustalık iklim yapısının başa çıkma stratejileri arasında yer alan çaba boyutu ile pozitif ve anlamlı ilişki gösterdiği de belirlenmiştir.

Sonuçlar, beden eğitimi dersinde, bireyin sahip olduğu beden eğitimi sınıf iklim yapısının problem çözme becerileri üzerinde etkili olduğu göstermektedir. Sonuç olarak, bireyin özellikle ustalık iklim yapısını destekleyecek ortamın oluşturulması, onun problem çözme konusunda daha etkili olmasına katkı sağlayacaktır. Bununla birlikte, beden eğitimi ve spor dersinin içeriğinin bu bağlamda ele alınarak düzenlenmesi ve öğrenci merkezli eğitim tarzının benimsenmesi, eğlenerek oyun anlayışında spor yapma ve fiziksel aktivite düzeylerinin arttırımasının çocukların ustalık iklim yapısının ve problem çözme becerisinin gelişimine etkisi olacağı düşünülmektedir.

\section{KAYNAKLAR}

1. Fidan, N., Erden, M. "Eğitime Giriş", Alkım Yayıncılık, Ankara, 1997.

2. D'Zurilla, T.J., Nezu, A.M., "Development and Preliminary Evaluation of the Social Problem-Solving Inventory. Psychological Assessment", A Journal of Consulting and Clinical Psychology, 2, pp.156-163, 1990.

3. Barut, Y., Yılmaz, M., "Beden Eğitimi ve Spor Bölümüne ve Eğitim Fakültesine Devam Eden Öğrencilerin Problem Çözme Becerilerinin Çeşitli Değişkenler Açısından İncelenmesi”. Uluslararası 1. Spor Bilimleri Kongresi Bildiriler Kitabı, pp. 26-27, 2000.

4. Miller, M., Nunn, G.D., "Using Group Discussions to Improve Social Problem-Solving and Learning”, Education (Chula Vista, Calif), 121, pp. 470-475, 2001.

5. Şahin, N., Şahin, N.H., Heppner, P.P., "Psychometric Properties of The Problem Solving Inventory in a Group of Turkish University Students", Cognitive Therapy and Research, 17 (4), pp. 379-396, 1993.

6. Dow, G.T., Mayer, R.E., "Teaching Students to Solve Insight Problems: Evidence for Domain Specificity in Creativity Training", Creativity Research Journal, 16, (4); pp. 389-13, 2004.

7. Savaşır, I., Şahin, N.H., "Bilişsel-Davranışçı Terapilerde Değerlendirme: Sık Kullanılan Ölçekler”, Ankara: Türk Psikologlar Derneği Yayınları, 1997.

8. Yıldız L., Zırhlıoğlu G., Yalçınkaya M., Güven Ş., "Beden Eğitimi Öğretmen Adaylarının Yaratıcılık ve Problem Çözme Becerileri”, 7. Ulusal Beden Eğitimi ve Spor Öğretmenlik Kongresi, Van/YYÜ Eğitim Fakültesi Dergisi Özel SayıSı, pp. 18-36, 2011.

9. Artistico, D., Orom H., Cervone D., Krauss S., Houston E., "Everyday Challenges in Context: The Influence of Contextual Factors on Everyday Problem Solving Among Young, Middle-Aged, and Older Adults", Experimental Aging Research, 36, pp. 230-247, 2010 . 
10. Ames, C., "Achievement Goals and The Classroom Climate". In J. Meece \& D. Schunk (Eds.), Student Perceptions in The Classroom, s. 327-348, Hillsdale, NJ: Eribaum, 1992.

11. Walling, M.D., Duda, J.L., Chi, L., "The Perceived Motivational Climate in Sport Questionnaire: Construct and Predictive Validity", Journal of Sport \& Exercise Psychology, Champaign, 15, pp. 172-183, 1993.

12. Morgan, K., Kingston, K., "Development of a Self-Observation Mastery Intervention Programme for Teacher Education", Physical Education and Sport Pedagogy, 13, pp. 109-129, 2008.

13. Ames, C., "Achievement Goals, Motivational Climate, and Motivational Processes". In G.C. Roberts (Ed.), Motivation in sport and exercise, s. 161-176, Champaign, IL: Human Kinetics, 1992.

14. Newman, R.S., "Students' Help Seeking During Problem Solving: Influences of Personal and Contextual Achievement Goals", Journal of Educational Psychology, 90(4), pp. 644-658, 1998.

15. Yıldız, S.A., "Ebeveynin Problem Çözme Becerisini Geliştirmeye Yönelik Deneysel Bir Çalışma”, Yayınlanmamış Doktora Tezi, İstanbul Üniversitesi Sosyal Bilimler Enstitüsü, İstanbul, 2003.

16. Çam, S., "iletişim Becerileri Eğitimi Programının Öğretmen Adaylarının Ego Durumlarına ve Problem Çözme Becerisi Algılarına Etkisi". Yayınlanmamış doktora tezi, Ankara Üniversitesi Sosyal Bilimler Enstitüsü, Ankara, 1997.

17. Dyson B.P., "Students' Voices in Two Alternative Elementary Physical Education Programs", Journal of Teaching in Physical, 14(4), pp. 394-407, 1995.

18. Karabulut E.O., Ulucan H., "Yetiştirme Yurdunda Kalan Öğrencilerin Problem Çözme Becerilerinin Çeşitli Değişkenler Bakımından İncelenmesi (Kırşehir İli Örneği)", Ahi Evran Üniversitesi Eğitim Fakültesi Dergisi, 12 ( 1), pp. 227-238, 2011.

19. Serin, O., Bulut Serin, N., Saygılı, G., “İlköğretim Düzeyindeki Çocuklar İçin Problem Çözme Envanteri'nin (ÇPÇE) Geliştirilmesi”, Illköğretim Online, 9 (2), pp. 446-458, 2010.

20. Goudas M., Biddle S., "Perceived Motivational Climate and Intrinsic Motivation in School Physical Education Classes", European Journal of Psychology of Education, 9, pp. 241-250, 1994.

21. Canpolat A.M., Kazak Çetinkalp Z., "Validity and Reliability of the Turkish Translation of The Physical Education Class Climate Scale", International Journal of Academic Research, 4 (1), pp. 89-95, 2012.

22. Haeffel, G.J., "Motion as Motivation: Using Repetitive Flexion Movements to Stimulate the Approach System", Behavior Therapy, 42(4), pp. 667-675, 2011.

23. Bell A.C, D'Zurilla TJ., "Problem Solving Therapy for Depression: A Meta - Analysis", Clinical Psychology Review, 29, pp. 348-353, 2009.

24. D'Zurilla T.J., Maydeu-Olivares A., Kant G.L., "Age and Gender Differences in Social Problem-Solving Ability", Personality and Individual Differences, 25 (2), pp. 241-252, 1998.

25. Güçray, S.S., "A Study of the Decision-Making Behaviors of Turkish Adolescents". Pastoral Care in Education, 23 (1), pp.34-44, 2005.

26. Moreno-Murcia, J.A., Hernández E.H., Vaillo R.R., Camacho, A.S., "Motivation and Physical Self-Concept in Physical Education: Differences by Gender", the Open Education Journal, 5, pp. 9-17, 2012.

27. Bakirtzoglou, P., loannou P., "Goal Orientations, Motivational Climate and Dispositional Flow in Greek Secondary Education Students Participating in Physical Education Lesson: Differences Based on Gender", Physical Education and Sport, 9, (3), pp. 295 $-306,2011$.

28. Moreno-Murcia, J.A., Gimeno, E.C., González-Cutre Coll, D., "Relationships among Goal Orientations, Motivational Climate and Flow in Adolescent Athletes: Differences by Gender", The Spanish Journal of Psychology, 11(1), pp. 181-191, 2008.

29. Ntoumanis, N., Biddle, S.J.H., Haddock, G., "The Mediating Role of Coping Strategies on the Relationship between Achievement Motivation and Affect in Sport. Anxiety, Stress, and Coping", An International Journal, 12, pp. 299-327, 1999.

30. Liukkonen, J., Barkoukis, V., Watt, A., Jaakkola, T., "Motivational Climate and Students', Emotional Experiences and Effort in Physical Education". The Journal of Educational Research, 103, pp. 295-308, 2010.

31. Standage, M., Duda, J. L., Ntoumanıs, N., "A Model of Contextual Motivation in Physical Education: Using Constructs from SelfDetermination and Achievement Goal Theories to Predict Physical Activity Intentions", Journal of Educational Psychology, 95, pp. 97-110, 2003.

32. Quested, E., Duda J.L., "Perceptions of the Motivational Climate Need Satisfaction, and Indices of Well- And III-Being among Hip Hop Dancers", J. Dance Med. Sci., 13, pp. 10-19, 2009.

33. Nicholls, J. G. "The Competitive Ethos and Democratic Education”. Cambridge, MA: Harvard University Pres, 1989. 